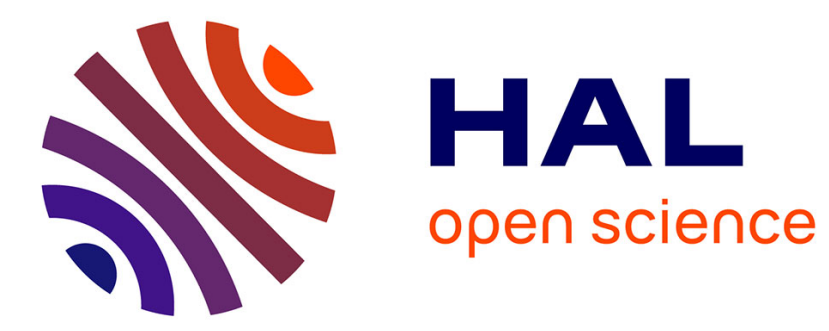

\title{
Dissociations and friction forces in metals and alloys
}

Alain Couret, Daniel Caillard

\section{To cite this version:}

Alain Couret, Daniel Caillard. Dissociations and friction forces in metals and alloys. Journal de Physique III, 1991, 1 (6), pp.885-907. 10.1051/jp3:1991163 . jpa-00248639

\section{HAL Id: jpa-00248639 https://hal.science/jpa-00248639}

Submitted on 1 Jan 1991

HAL is a multi-disciplinary open access archive for the deposit and dissemination of scientific research documents, whether they are published or not. The documents may come from teaching and research institutions in France or abroad, or from public or private research centers.
L'archive ouverte pluridisciplinaire HAL, est destinée au dépôt et à la diffusion de documents scientifiques de niveau recherche, publiés ou non, émanant des établissements d'enseignement et de recherche français ou étrangers, des laboratoires publics ou privés. 
Classification

Physics Abstracts

$81.40 \mathrm{~L}$

\title{
Dissociations and friction forces in metals and alloys*
}

\author{
A. Couret and D. Caillard \\ CEMES-LOE-CNRS, 29 Rue J. Marvig, BP 4347, 31055 Toulouse Cedex, France
}

(Received 17 May 1990, accepted 9 November 1990)

\begin{abstract}
Résumé. - 50 ans après la première idée de base de Peierls, nous faisons une revue des différents aspects des forces de friction dans les métaux et les alliages. Les diverses approches sont comparées, et nous montrons que toutes conduisent à des résultats semblables, correspondant à deux comportements différents dans deux domaines de température. Les résultats expérimentaux dans les métaux $\mathrm{CC}, \mathrm{HC}$ et $\mathrm{CFC}$ sont en bon accord avec ces développements théoriques. Dans une seconde partie, nous développons une extension du modèle de Peierls, appelée blocagedéblocage, sur la base de résultats expérimentaux obtenus dans les plans prismatiques du béryllium. Elle s'applique à de nombreuses autres situations, telles que le glissement prismatique du magnésium et du titane, le glissement cubique et octaédrique des alliages ordonnés $\mathrm{Ll}_{2}$ à base nickel, et peut-être quelques métaux $\mathrm{CC}$. Nous discutons la relation entre les mécanismes de blocage-déblocage et de Peierls, ainsi que le rôle du blocage-déblocage dans la formation des anomalies de limite élastique.
\end{abstract}

Abstract. - 50 years after the first basic idea of Peierls, a review is made on the different aspects of friction forces in metals and alloys. Different approachs are compared, and it is shown that all lead to similar results, corresponding to different behaviours in two stress ranges. Experimental results in BCC, HCP, and FCC metals, are in good agreement with these theoretical developments. In a second part, an extension of the Peierls model, called locking-unlocking, is developed on the basis of experimental results in the prismatic planes of beryllium. It applies to many other situations, such as prismatic glide in magnesium and titanium, cube and octahedral glide in $\mathrm{L}_{2}$ nickel-based ordered alloys, and possibly some $\mathrm{BCC}$ metals. The relation between locking-unlocking and Peierls mechanisms is discussed, as the role of locking-unlocking in the formation of strength anomalies.

\section{Introduction.}

Motions of dislocations, submitted to friction forces resulting from their non planar dissociation or spreading, play a very important role in the deformation of materials (see, for instance, reviews [1-4]). Plastic properties of BCC metals, as well as the strong temperature dependence of the flow stress, have been explained by the non-planar core structure of screw dislocations [1, 5-7]. The Peierls mechanism has been proposed as the controlling mechanism

(*) This article is dedicated to Prof. R. E. Peierls, for the 50th anniversary of "Peierls friction forces ». 
for both prismatic glide and creep at low temperatures of magnesium [8, 9]. The same mechanism has also been considered as an explanation for several plastic properties of FCC metals : motion of Lomer-Cotrell barriers, glide in non-compact planes, third stage of deformation and/or creep at intermediate temperatures (see reviews in [10-12]). In his review article largely devoted to ordered alloys and superalloys with $\mathrm{DO}_{19}, \mathrm{~B}_{2}, \mathrm{Ll}_{2}$ or $\mathrm{Ll}_{0}$ structure, Veyssière [4] has shown that the plasticity of these materials is generally dominated by dislocation core effects. Hence, it appears that only the compact glide of the FCC structure and the basal glide of some HCP metals have no bearing on friction forces. Moreover, the more complicated the material structure, the more inevitable and essential is the role of the interaction between dislocations and the crystal lattice. Thus, the plasticity of intermetallic materials which are at present extensively studied because of both their fundamental interest and their excellent properties, cannot be understood without considering friction forces.

In this article, attention will be focussed on experimental and theoretical aspects of friction forces in metals and alloys. The case of covalent materials (semiconductors, ceramics) is treated by George, in this conference. Section 1 will briefly recall and compare the main models outcoming from the Peierls theory. In section 2, a new friction force mechanism called "locking-unlocking» will be presented. The correlation between Peierls and lockingunlocking mechanisms and between friction forces and strength anomalies will be respectively discussed in sections 3 and 4 .

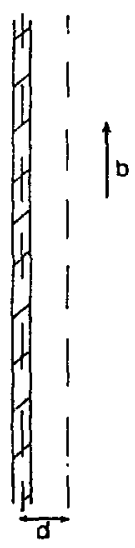

a

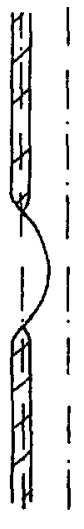

b

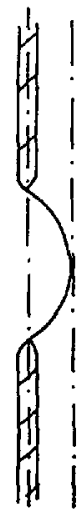

c

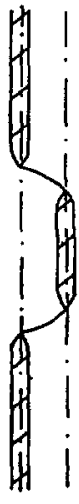

d

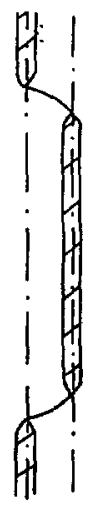

$\boldsymbol{e}$

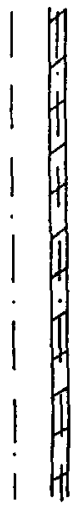

f

Fig. 1. - Scheme of the Peierls mechanism. Six successive configurations of one dislocation, for one jump between two adjacent Peierls valleys.

\section{Peierls mechanism.}

In the case of the original Peierls mechanism [13, 14], dislocations have their minimum energy in -the so-called "Peierls valleys » and their motion can be described as series of jumps between adjacent valleys. The resulting friction force has the lattice periodicity. In the early model, it is assumed that dislocations are spread in their glide plane. As the friction force varies as the inverse of the core width in the glide plane and as the dissociation width is largest for the most closely packed planes, friction forces are lower in compact planes. This model seemed to explain experimental observations of glide in the compact planes of HCP and FCC metals. Later, Seeger [15] showed that dislocations could jump between adjacent Peierls valleys, through the thermally activated nucleation and propagation of kinks pairs. However, 
it appears that when dislocations glide in their dissociation plane, the early model of Peierls and Nabarro can account only for very low friction forces and cannot explain many mechanical properties.

More recent studies have shown that larger friction forces resulting from the dissociation or spreading of dislocations out of their glide plane play a more important role in plasticity (Fig. 1). In this case, as in the early model of Peierls and Nabarro, the friction force has the lattice periodicity. This mechanism was proposed for the first time by Hirsch [16] and Yoshinaga and Horiuchi [17] for BCC and HCP metals. It has been also called " Pseudo Peierls », double kink, kinks pair, jogs pair, " Friedel-Escaig » or more simply Peierls mechanism. In the following, we will use the term Peierls mechanism. In the sixties, the main theoretical developments were obtained after the study of glide in BCC metals and prismatic glide of HCP metals such as magnesium. The main features of these glide systems are a strong decrease of the critical resolved shear stress as the temperature is increased and the occurrence of a homogeneous density of screw dislocations (see for instance BCC : $[6,7,18$ 20]; HCP : [21-23]).

When the deformation is controlled by such friction forces, dislocations must overcome obstacles resulting from their dissociation. According to Escaig [24], the analysis of this mechanism requires the determination of the corresponding critical metastable configuration for the dislocation movement. This allows in principle the evaluation of the activation area and energy. As shown in figure 2, the dislocation energy $U$ is the sum of the kink pair energy $H_{\mathrm{kp}}$ and the work of the applied shear stress $W=-\sigma b x$. The dislocation energy passes through a maximum which gives the activation energy $\Delta G$ of the mechanism. The length $x_{\mathrm{c}}$ is the kink pair separation for the critical metastable configuration. It is proportional to the activation area $A$. According to the different models, and as a function of the stress level, the critical metastable configuration could be either a dislocation loop bowing out in the glide plane (Fig. 1b or c) or a pair of kinks more or less well separated (Fig. 1d or e). The corresponding theoretical model will be different (Tab. I).

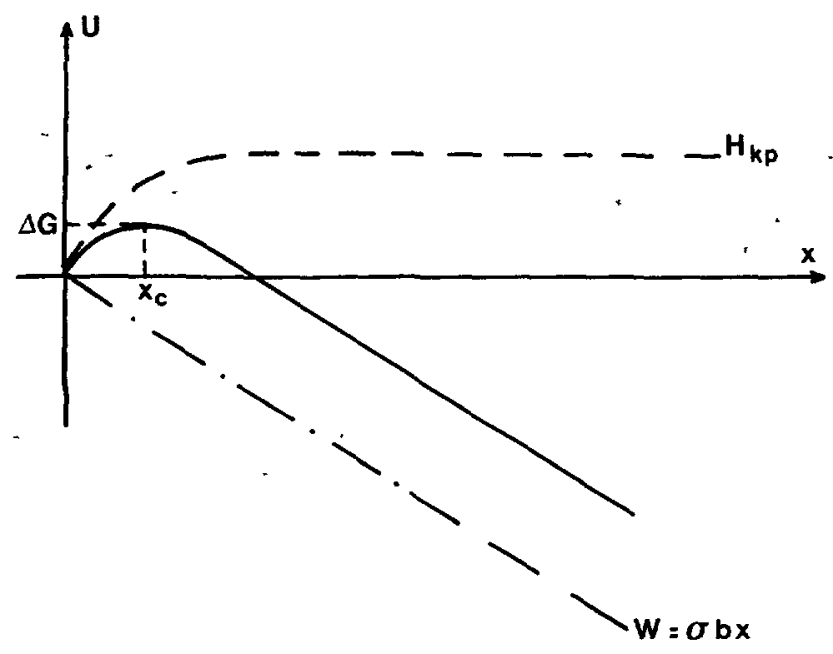

Fig. 2. - Energy $U$ of a dislocation as a function of the kinks separation $x: H_{\mathrm{kp}}$ is the kink pair energy under zero stress, $W$ the work of the shear stress, $\Delta G$ the activation energy and $x_{c}$ the critical kink separation. 
Table I. - Critical configurations, theoretical models, activation area and experimental results for the two stress ranges of the Peierls mechanism.

\begin{tabular}{|c|c|c|c|c|}
\hline & \multicolumn{2}{|c|}{ High stress $\left(\sigma>\sigma_{c}\right)$} & \multicolumn{2}{|c|}{ Low stress $\left(\sigma<\sigma_{c}\right)$} \\
\hline $\begin{array}{c}\text { Critical } \\
\text { Configurations }\end{array}$ & $\begin{array}{l}1 \\
1 \\
1 \\
1 \\
1 \\
1\end{array}$ & 政 & & \\
\hline & CROSS SLIP & LINE TENSION & KIN & PAIR \\
\hline $\begin{array}{l}\text { Theoretical } \\
\text { Models }\end{array}$ & $\begin{array}{c}\text { Friedel } \\
\text { [25] (1959) } \\
\\
\text { Duesbery } \\
\text { Hirsch } \\
\text { [5] (1967) } \\
\text { Escaig } \\
\text { [29] (1967) } \\
\\
\text { Schoëck } \\
\text { Püschl } \\
\text { [28] (1988) }\end{array}$ & $\begin{array}{c}\text { Seeger } \\
\text { [26] (1981) }\end{array}$ & $\begin{array}{c}\text { Kink } \\
\text { interaction } \\
-\quad 1 / \mathbf{r} \\
\text { Duesbery } \\
\text { Hirsch } \\
\text { [5] (1967) } \\
\text { Seeger } \\
\text { [26] (1981) } \\
\text { Schö̈ck } \\
\text { Püschl } \\
\text { [28] (1988) } \\
\text { Duesbery } \\
\text { [32] (1983) }\end{array}$ & $\begin{array}{c}\text { Kink } \\
\text { interaction } \\
\text { Log r } \\
\text { Escaig } \\
\text { [24] (1968) } \\
.\end{array}$ \\
\hline $\begin{array}{l}\text { Activation Area } \\
\text { dependences }\end{array}$ & $\sigma^{-2}$ & $\log (1 / \sigma)$ & $\sigma \cdot 1 / 2$ & $\sigma^{-1}$ \\
\hline $\begin{array}{l}\text { Experimental } \\
\text { Results }\end{array}$ & $\begin{array}{c}\begin{array}{c}\text { Kubin } \\
\text { Jouffrey } \\
\text { [20] (1973) }\end{array} \\
\text { Biget } \\
\text { Saada } \\
\text { [43] (1989) }\end{array}$ & $\begin{array}{c}\text { Wemer } \\
\text { Seeger } \\
\text { [30] (1988) } \\
\\
\text { Ackerman } \\
\text { Mugrabi } \\
\text { Seeger } \\
\text { [31] (1983) }\end{array}$ & $\begin{array}{c}\text { Werner } \\
\text { Seeger } \\
\text { [30] (1988) } \\
\\
\text { Ackerman } \\
\text { Mugrabi } \\
\text { Seeger } \\
\text { [31] (1983) }\end{array}$ & $\begin{array}{c}\text { Kubin } \\
\text { Jouffrey } \\
{[20](1973)}\end{array}$ \\
\hline
\end{tabular}

\subsection{THEORETICAL MODELS.}

1.1.1 High stress $\left(\sigma>\sigma_{c}\right)$. - If the height of the critical configuration is less than the distance between two neighbouring Peierls valleys (Fig. $1 \mathrm{~b}$ or $\mathrm{c}$ ) the deformation mechanism could be described by the cross slip model proposed by Friedel for the prismatic glide of HCP metals [25]. The energy is the sum of the energy spent to recombine the dislocation over a length $\ell$ and the energy gained by bending the dislocation in the glide plane. By neglecting the 
dissociation energy in the glide plane and the effect of the applied stress on the dissociation width, the activation energy $\Delta G$ and the activation area $A$ can be expressed as:

$$
\Delta G=U_{\mathrm{c}}+\frac{2^{5 / 2} r^{3 / 2} \tau^{2}}{3 \sigma b} \quad A=\frac{2^{5 / 2} r^{3 / 2} \tau^{2}}{3 \sigma^{2} b^{2}}
$$

where $U_{\mathrm{c}}$ is the constriction energy in the Peierls valley, $\tau$ is the line tension, $r=R / \tau$, $R$ the energy of dissociation per unit length in the Peierls valley (absolute value), and $\sigma$ is the shear stress in the glide plane. The activation energy varies as the inverse of the applied stress and the activation area as the inverse of the stress squared.

Another model has been proposed by Seeger [26-27]. It assumes that the critical configuration is a kink pair even at high stresses. However, since the kink separation is small, it cannot be described in terms of linearized elasticity theory and the kink interaction is studied in the "line-tension » approximation. The activation area varies as $\log (1 / \sigma)$ which is different from that of the Friedel model.

Both models have been compared in table I.

1.1.2 Low stress $\left(\sigma<\sigma_{c}\right.$ ). - As first mentioned by Duesbery and Hirsch [5], the dislocation could reach the next Peierls valley and take again its initial sessile core configuration before the critical configuration is attained. In this case, the critical configuration is described by the formation of two kinks separated by a critical distance (Fig. 1d or e) (Escaig [24]). Various treatments which differ in their initial assumptions on the nature of the kinks interaction at the critical configuration have been proposed (Tab. I). The models can be classified into two groups depending on this choice. An interaction which varies as the inverse of the kink separation has been used by Duesbery and Hirsch [5], Seeger [26-27] and Schöeck and Püsch1 [28]. The corresponding activation area varies as $\sigma^{-1 / 2}$. On the other hand, Escaig [24] assumes a logarithmic dependence and takes into account the interaction between constrictions when the kinks separation is small. He obtains a variation as $\sigma^{-1}$ for the activation area. It must be noted that here again the two variations of the activation area are different.

1.2 DisCUSSION. - For the two stress ranges, several detailed models have been developed especially in the case of BCC and HCP metals. In many cases, experimental results have been used in order to determine some parameters relating to the core structure of dislocations. These models and several experimental studies will be discussed here with the help of table I and figure 3 which shows results obtained for single crystals of Niobium (BCC structure).

1.2.1 BCC metals. - First, it is worth noting that every theoretical and experimental study leads to an abrupt change of slope for the variation of the CRSS with temperature (Fig. 3a) which is correlated with a discontinuity in the activation area curve (Fig. $3 \mathrm{~b}$ ). This change corresponds to the change of critical configuration described previously, depending on the stress level.

In the high stress and low temperature range, Friedel's theory has been fully developed by Escaig [29] and Duesbery and Hirsch [5] using the non planar core configuration of BCC metals. These calculations yield to curves which are markedly different (Fig. 3a, at low temperatures) owing to different assumptions on the stacking fault energy value. Escaig's value results from the extrapolation of experimental curves. The experimental curve of Kubin and Jouffrey [20] has also been plotted on the figure. It is close to Escaig's one, but the corresponding activation areas (Fig. 3b) are markedly different. Unfortunately, no experimental results and no theoretical values of the Seeger's group are available in Niobium in the high stress range. The comparison of all these models is thus impossible. However, it must be 


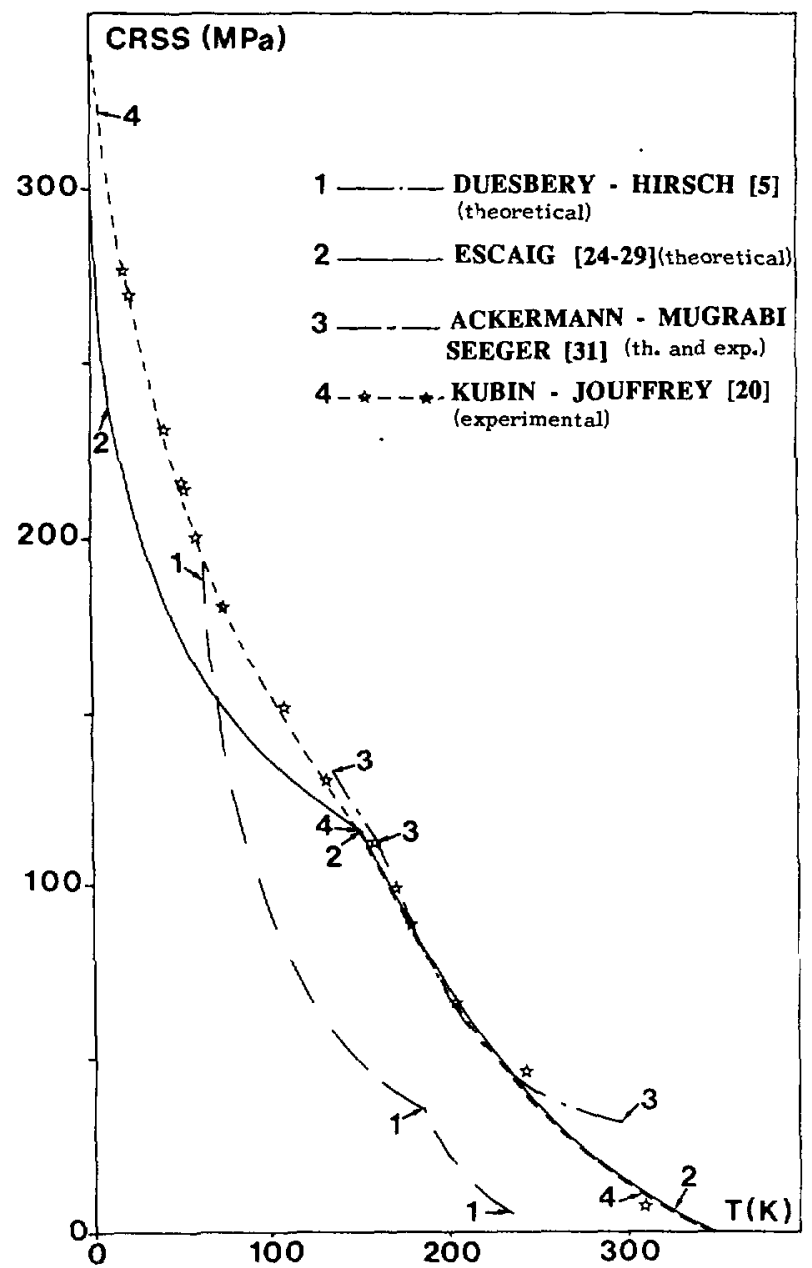

a)

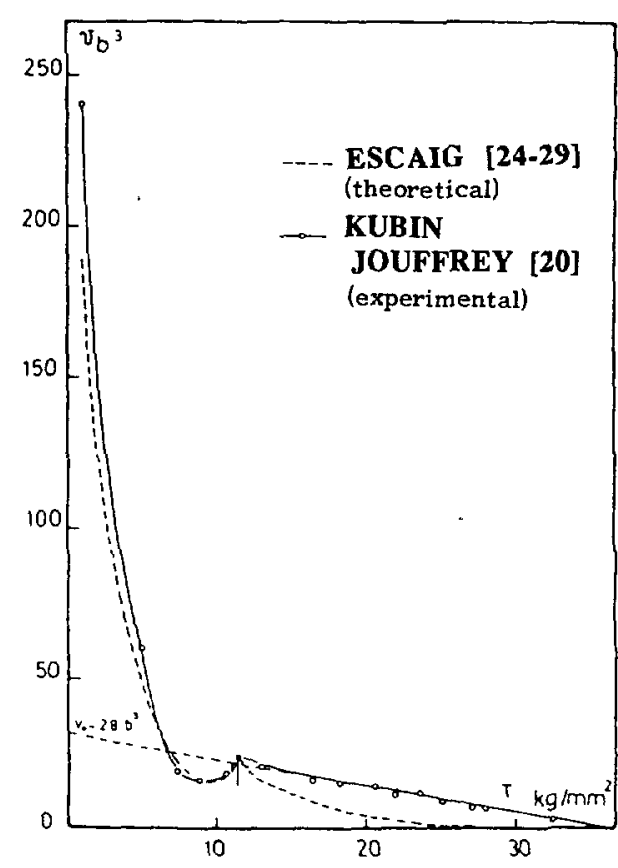

b)

Fig. 3. - For Niobium single crystals, comparison between different theoretical and experimental variations of : a) CRSS as a function of temperature, b) activation area as a function of stress.

noted that in Tantalum the experimental work of Werner and Seeger [30] fits very well with the « line tension » model.

In the low stress and high temperature range, the models described above have been fully developed in the case of the BCC structure [5, 24, 26, 27] (Fig. 3a). For the same reason as in the high stress range, the simplified model of Duesbery and Hirsch yields results which are quantitatively different from the other contributions. On the other hand, Escaig's treatment [24] and Seeger's one [26, 27] which, as mentioned above, are based on different assumptions, lead to very close curves. The experimental results obtained by Kubin and Jouffrey [20] and by Ackermann, Mugrabi and Seeger [31] also fit very well theoretical curves. Moreover, all these contributions agree with an increase of the activation area as a function of the stress, near the critical stress. In this range, experimental results of Kubin and Jouffrey [20] are close to the theoretical curve of Escaig [24] (Fig. 3b). Near the critical stress (Fig. 3b), Escaig assumes that the critical configuration is controlled by the constriction interaction, and describes successfully the transition between the two stress ranges. 

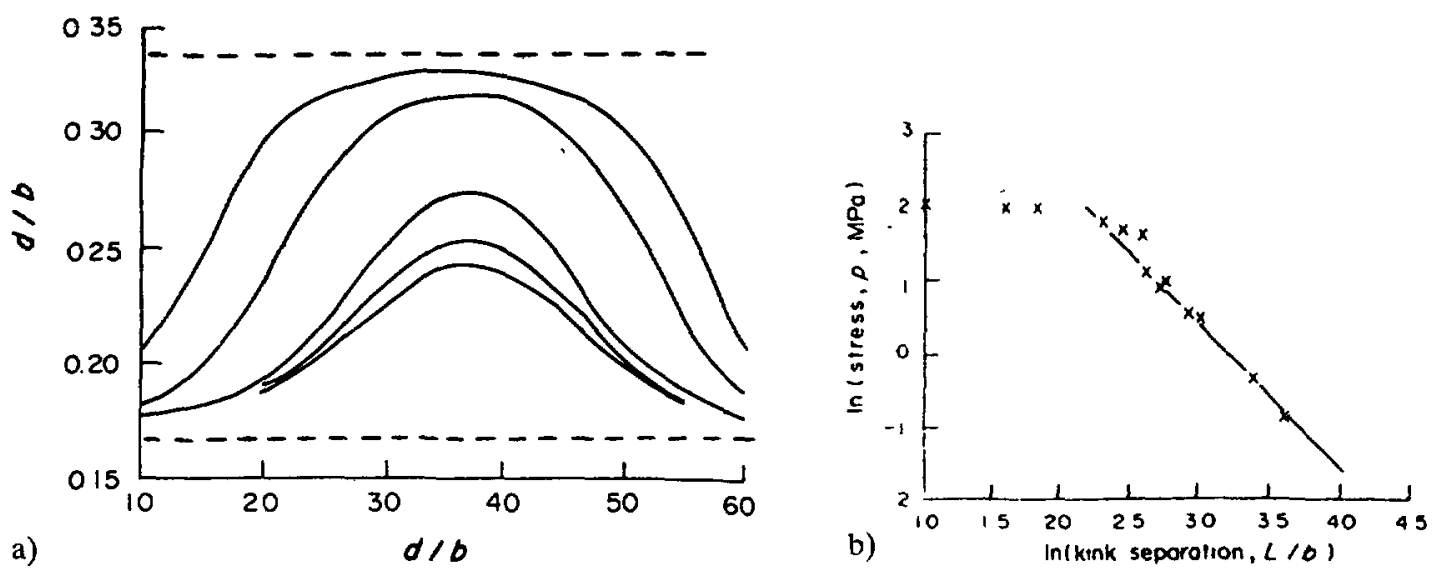

Fig. 4. - Duesbery [32, 34] : computed kink pair properties in Potassium a) Different critical configurations for different applied shear stresses. b) Logarithmic plot of the kink-kink interaction force as a function of kink separation.

The core structures and the self and interaction energies of kinks on screw dislocations in a BCC lattice have been computed by Duesbery [32-34], using a model representing both Potassium and Iron. Figure 4a shows the kinks pair configurations calculated in Potassium for a variety of kinks separations. Two regimes have been pointed out. If the kinks separation is less than $20 \mathrm{~b}$, or about 1.5 kinks width, the double kink behaves more like a single defect. If the kink separation is larger, two kinks well separated are obtained. These two regimes correspond to the two stress ranges described above. The equilibrium relation between the applied stress and the kinks separation are plotted on figure $4 \mathrm{~b}$. Of greater interest is the observation of the same two ranges of behaviour and that an inverse square law is valid for the variation of the kinks separation as a function of stress in the low stress range, in agreement with a variation of the kink interaction energy as the inverse of kinks separation, as also assumed by Duesbery and Hirsch [5], Seeger [26, 27] and Schöeck and Püsch] [28].

In situ tensile experiments have been performed at different temperatures by Louchet $e t$ al. on Niobium, Molybdenum and $\alpha$-Iron $[35,36]$ and by Ikeno and Furubayashi on Niobium and $\mathrm{Fe}-3 \% \mathrm{Si}[37,38]$. Slow movements of rectilinear screw dislocations and fast movements of mixed dislocations habe been observed. This behaviour has been interpreted in terms of a Peierls mechanism.

1.2.2 HCP Metals. - For HCP -metals, Schöeck and Püschl [28] have calculated the activation energies for both models (the cross slip model of Friedel and the kinks pair model), by using the line tension calculated in à previous work [39] (Fig. 5). These calculations confirm that the high stress range is controlled by the cross slip model and the low stress range by the kinks pairs model. In the next paragraph, the Schöeck and Püschl model will be compared with experimental results for HCP metals.

In situ experiments have shown that the prismatic glide of Magnesium is controlled by the smooth and continuous motion of rectilinear screw dislocations submitted to a strong friction force (Fig. 6) [8, 9]. This study leads to the conclusion that the strain rate is controlled by the double-kink mechanism (low stress range). Microscopic values of activation area $\left(9 \mathrm{~b}^{2}\right.$ at $300 \mathrm{~K})$ and activation enthalpy $(0.8 \mathrm{eV}$ at $336 \mathrm{~K})$ deduced from the analysis of single dislocations movements are in excellent agreement with those deduced from all detailed models. Assuming a kink height of $h=c$ and not $h=c / 2$, calculations of Schöeck and Püschl 


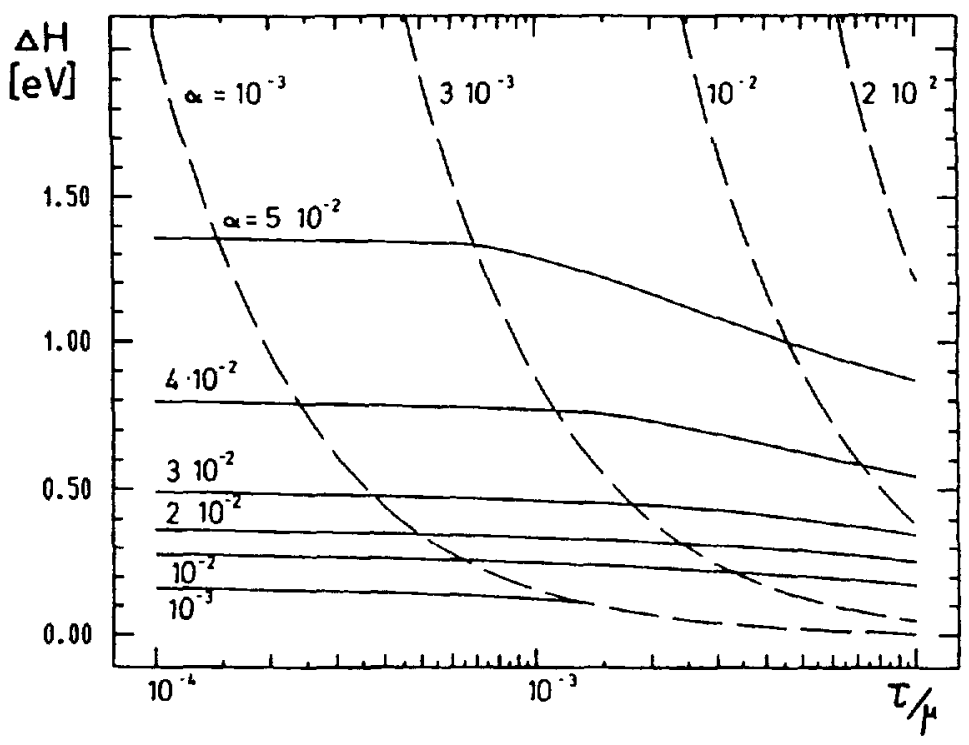

Fig. 5. - Schöeck and Püschl [28] : Activation enthalpies for cross slip (dotted lines) and kinks pair formation (full lines) in Magnesium as a function of $\tau / \mu\left(\alpha=R / \mu b^{2}\right)$.

[28] yield some values of the activation parameters which agree very well with the experimental ones.

Naka et al. [40-42] have concluded that the prismatic glide of $\alpha$-Titanium is governed by a Peierls mechanism acting on screw dislocations. This work points out singularities between 300 and $500 \mathrm{~K}$ in both CRSS and activation area versus temperature curves (Fig. 7) which are associated with an extensive of cross slip. They have been recently interpreted in terms of dynamic strain ageing. However, they also might be connected to the transition between the low and high stress regimes described above in the case of BCC metals. It must be noted that an explanation of these discontinuities must point to their very large amplitude and the high temperature at which they occur. In the low temperature range, Biget and Saada [43] have
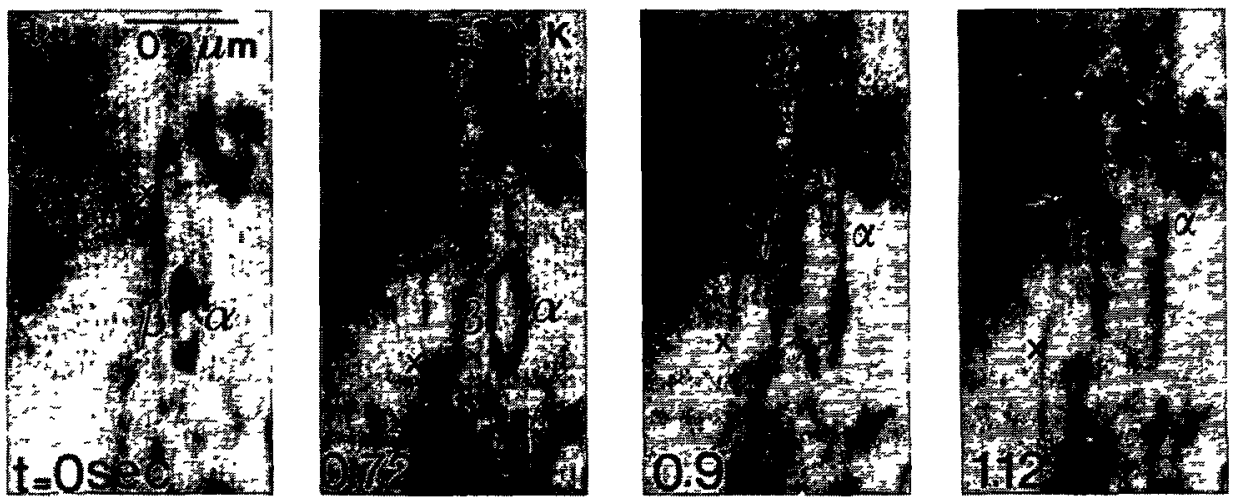

Fig. 6. - Evidence of a Peierls mechanism on screw dislocations in Prismatic planes of Magnesium, at $T=300 \mathrm{~K}$. 
a)

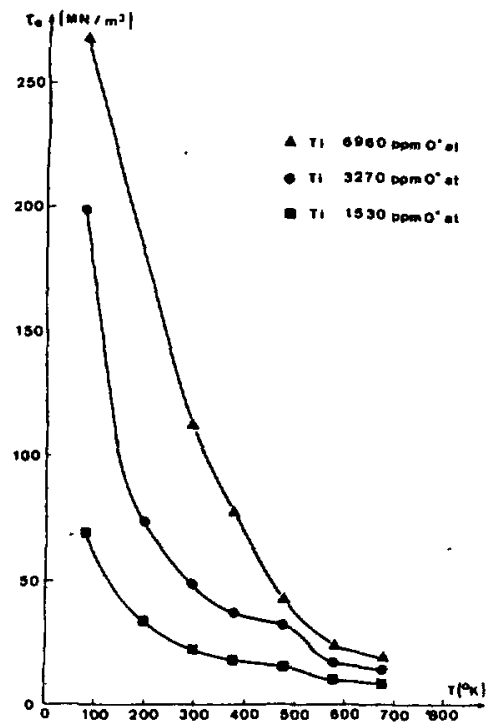

b)

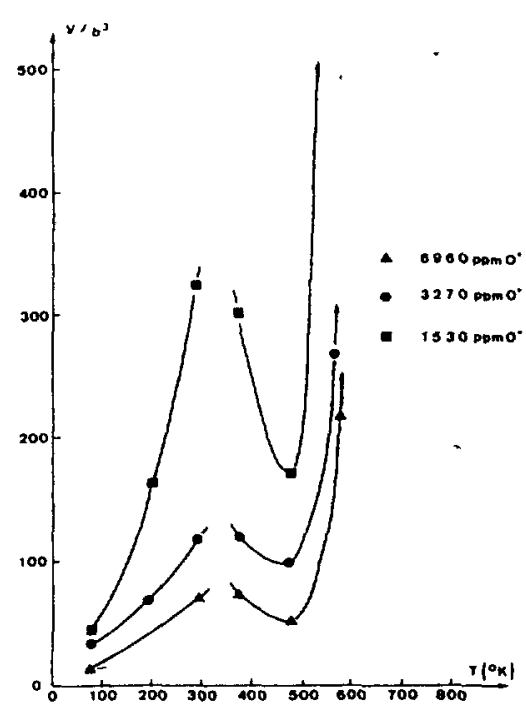

Fig. 7. - Naka [40-42] : Prismatic glide of Titanium : a) Variation of the CRSS as a function of temperature, b) Variation of the activation area as a function of temperature.

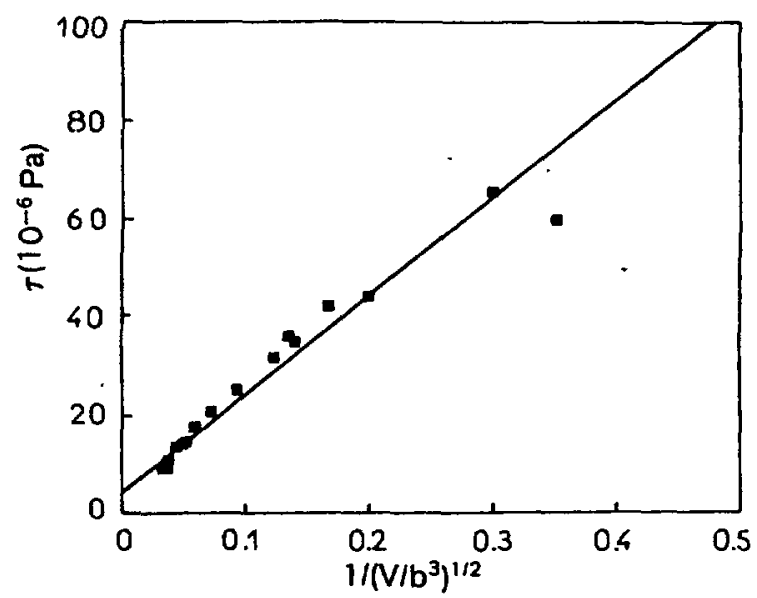

Fig. 8. - Biget and Saada [43] : Prismatic glide of Titanium. Variation of the CRSS as a function of $\left(V / \mathbf{b}^{3}\right)^{-1 / 2}(V:$ activation volume $)$.

found an inverse square law variation of the activation area as a function of the applied stress (Fig. 8), which agrees with the cross slip mechanism.

1.2.3 FCC Metals. - The existence of Peierls friction forces is generally less commonly accepted in FCC metals than in BCC and HCP metals. This is mainly due to the abundance of the $\langle 110\rangle\{111\}$ easy glide systems in the FCC structure, which can in principle accomodate any applied deformation.

However, experiments of Le Hazif and Poirier [44, 45], in several pure FCC metals strained along $\langle 100\rangle$, have shown that extensive glide in non compact $\{110\}$ planes can occur above a 
critical temperature, which is closely related to the stacking fault energy. Further experiments of Carrard and Martin [46-48], in aluminium strained along 112$\rangle$, confirm that dislocations multiply and move in the $\{100\}$ planes of highest Schmid factors, independently of glide in $\{111\}$ compact planes, and that the corresponding CRSS strongly decreases as the temperature is increased. This behaviour has been clearly explained by a Peierls mechanism, with screw dislocations extended in one of the two possible $\{111\}$ planes, and moving in non compact planes by nucleating and propagating kinks pairs.

A direct confirmation of the existence of non compact glide at a microscopic scale has been given after in situ experiments in aluminium (Couret and Caillard [49]).

1.3 CONCLUSIONS. - The first major conclusion of this review is a very large consistence between all mentioned theoretical and experimental contributions. Many of them conclude in favour of a change of behaviour for a critical stress which is correlated to a change of controlling mechanism.

In the high stress range, the quantitative agreement between the different results is not very good even if all treatments, except the Seeger one, derive from the Friedel theory.

In the low stress range, althought the initial assumptions are different, the main contributions lead to very close results. A discrimination between the two possible kink interactions cannot be made at present. Since all models yield close values of the activation enthalpy, the measurement of this parameter does not allow to identify the correct one. On the contrary, the measurement of the activation area and its variation as a function of stress might give some precious indications about the controlling mechanism.

\section{Locking-unlocking mechanism.}

2.1 Prismatic Glide of Beryllium. - The prismatic glide of Beryllium (HCP metal) has been studied by in situ experiments in a JEOL $200 \mathrm{CX}$ electron microscope [50-52]. Microsamples are cut from single crystals, and oriented so as to inhibit basal glide, which is the easiest glide system in this material $[53,54]$. The basal plane is normal to the thin foil and the tensile axis is parallel to [10 $\overline{1} 0]$.

Figure 9 shows that the deformation in prismatic planes of beryllium at room temperature is controlled by the motion of rectilinear screw dislocations submitted to a strong friction force. This behaviour is a priori similar to that occuring in Magnesium above room temperature (Fig. 6). However, it is fundamentally different, in that the movement of screw dislocations is no longer smooth and continuous, but jerky. For instance, one dislocation appears immobile in successive positions $\mathrm{a}, \mathrm{c}, \mathrm{e}, \mathrm{g}, \mathrm{h}, \mathrm{j}$ and jumps so suddenly in less than $1 / 50 \mathrm{~s}$ (one frame), that it is visible on one frame in both starting and final position (Fig. $9 b, d, f, h, i)$. The waiting time between two jumps is always larger than the flight time and varies between $1 / 50$ and $2 \mathrm{~s}$.

The dislocation slip traces exhibit segments parallel to the traces of prismatic and basal planes, respectively (Fig. 10). This proves that dislocations glide in prismatic planes during jumps (Fig. 9). This also indicates that screw dislocations move in basal planes during waiting times between jumps in prismatic planes. Basal glide does not however appear, on figure 9 , since the basal plane is edge on. It is much slower than jumps in prismatic planes, since it occurs only under residual or internal stress.

2.2 THE LOCKING-UNLOCKING MECHANISM. - The above experimental results show that screw dislocations take alternately two configurations of different energies, corresponding to a core spreading (or dissociation) in prismatic and basal planes respectively. The glissile configuration in the prismatic plane has a very short lifetime and a high energy (metastable 

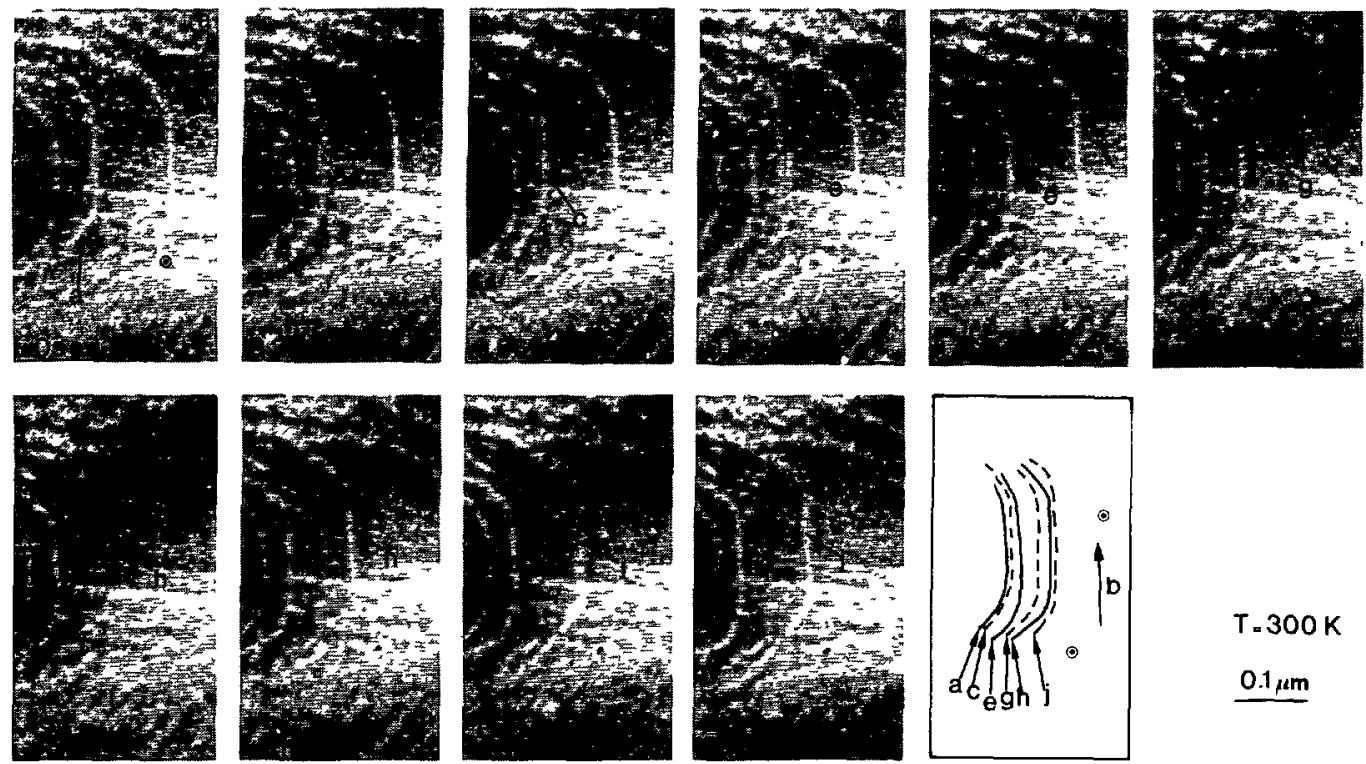

$\mathrm{T} .300 \mathrm{~K}$

$\underline{0.1 \mu \mathrm{m}}$

Fig. 9. - Evidence of a locking-unlocking mechanism on screw dislocations in prismatic planes of Beryllium. Letters refer to successive positions of the same dislocation. $T=300 \mathrm{~K}$.

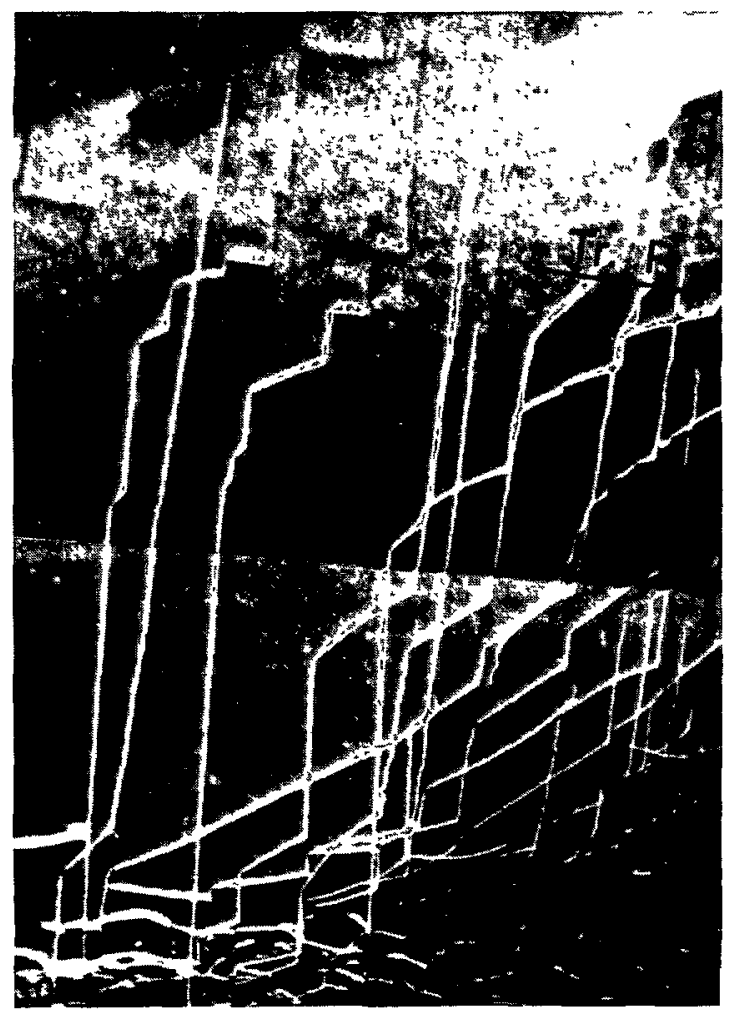

Fig. 10. - Slip traces parallel to the traces of prismatic (P) and basal (B) planes, after the movement of screw dislocations and the emergence of superkinks. Beryllium, $T=300 \mathrm{~K}$. 
configuration), whereas the most usual configuration is glissile in the basal plane, and has a lower energy (stable configuration). This is in full agreement with calculations of Legrand [55, 56], yielding a higher stacking fault energy in the prismatic plane than in the basal plane. Under such conditions the locking and the unlocking of screw dislocations are two fundamental different cross slip processes, as pointed out by Escaig [1]. The whole lockingunlocking mechanism is described step by step in the next paragraph with reference to figure 11.

a) Locked dislocation (Fig. 11a): The dislocation is spread in the basal plane, i.e. in its stable configuration of long life time. It can glide in the basal plane under residual or internal stresses.

b) Unlocking (Fig. $11 b \& c$ ) : The unlocking process, which is a cross slip onto a plane of higher stacking fault energy, can be described by the Friedel mechanism presented in $\$ 1.1 .1$. The dislocation must overcome a threshold energy corresponding to the activation energy of this mechanism $\left(\Delta G_{\mathrm{ul}}=\Delta G_{\text {Friedel }}\right)$.

c) Jump by glide in the prismatic plane (Fig. 11d): The screw dislocation is slightly spread in the prismatic plane (metastable configuration). During a very short time, it glides freely and rapidly under a high stress which is equal to the component of the applied stress in the prismatic plane.

d) Locking (Fig. 11e \&f) : According to Escaig [1], this cross slip process is different from the preceding one, since it occurs onto a plane of lower stacking fault energy. It is similar to that occurring between $\{111\}$ planes in FCC metals, where a stress dependent effective stacking fault energy can be defined; as soon as one constriction is produced with the help of
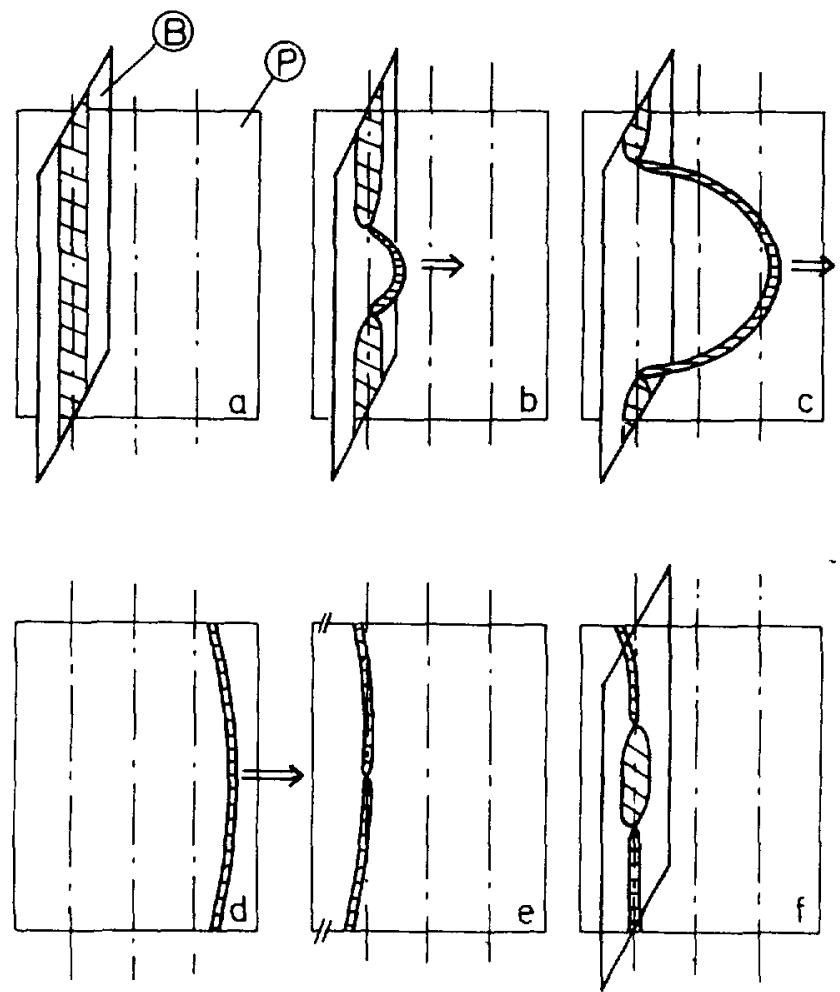

Fig. 11. - Schematic diagram of the locking-unlocking mechanism. 
thermal activation, the dislocation tends to widen in the cross slip (basal) plane, thus lowering its core energy. The two constrictions then move rapidly towards dislocations extremities. The activation energy is of the order of the constriction energy in the prismatic plane $\left(\Delta G_{I} \approx U_{\mathrm{cp}}\right)$. It is much lower than the unlocking one.

e) Energy diagramm (Fig. 12): The stable and metastable configurations are separated by two different threshold energies, thus defining two activation energies which correspond to unlocking $\left(\Delta G_{u l}\right)$ and locking $\left(\Delta G_{1}\right)$ processes, respectively. The unlocking energy is larger than the locking one, in agreement with a waiting time larger than the jump time. Since locking and unlocking are described by two fundamentally different processes, locking does not appear as the reverse of unlocking. On figure 12, the threshold energy of unlocking, has been arbitrarily pictured lower than that corresponding to the reverse of unlocking. A similar energy diagram has been proposed by Hug et al. $[57,58]$ in order to explain the strength anomaly of TiAl.

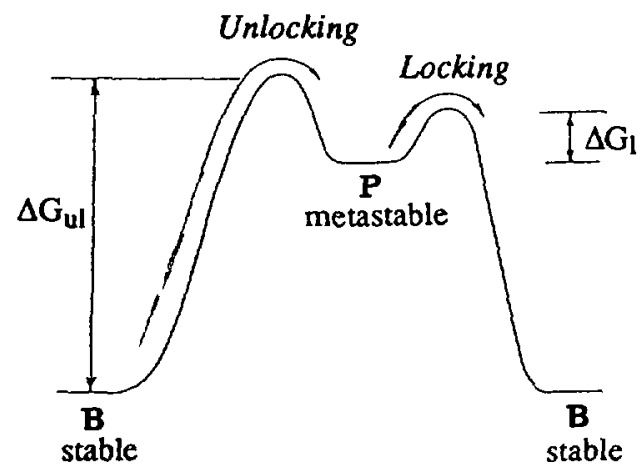

Fig. 12. - Energy diagram representing the different core configurations and the two cross-slip processes.

f) Velocity of dislocations: Since the two processes act in series, the average velocity of screw dislocations can be expressed as:

$$
V=V_{\mathrm{P}} \frac{\bar{t}_{\mathrm{P}}}{\bar{t}_{\mathrm{P}}+\bar{t}_{\mathrm{B}}} \approx V_{\mathrm{P}} \frac{\bar{t}_{\mathrm{P}}}{\bar{t}_{\mathrm{B}}} \approx \frac{\bar{\lambda}}{\bar{t}_{\mathrm{B}}}
$$

where $V_{\mathrm{P}}$ is the instantaneous dislocation velocity during the jump in the prismatic plane, $\bar{t}_{\mathrm{P}}$ the average flight time in the prismatic plane, $\bar{t}_{\mathrm{B}}$ the average locking time in the basal plane and $\bar{\lambda}$ the average flight length.

Using :

$$
\frac{1}{\bar{t}_{\mathrm{P}}}=P_{1}=P_{01} \exp -\frac{\Delta G_{1}}{k T} \text { and } \quad \frac{1}{\bar{t}_{\mathrm{B}}}=P_{\mathrm{ul}}=P_{0 \mathrm{ul}} \exp -\frac{\Delta G_{\mathrm{ul}}}{k T}
$$

where $P_{u l}$ and $P_{1}$ are unlocking and locking probabilities, respectively, the dislocation velocity can be expressed as:

$$
V=V_{0} \exp -\frac{\Delta G_{1-\mathrm{ul}}}{k T}, \text { with } \Delta G_{1-\mathrm{ul}}=\Delta G_{\mathrm{ul}}-\Delta G_{1} .
$$


Since $\Delta G_{\mathrm{ul}} \gg \Delta G_{1}$, the activation parameters of the locking-unlocking mechanism are close to those of unlocking. We thus obtain :

and

$$
\begin{aligned}
\Delta G_{1-\mathrm{ul}} & =\Delta G_{\mathrm{ul}}-\Delta G_{1} \approx \Delta G_{\mathrm{ul}}=\Delta G_{\text {Friedel }} \\
A_{1-\mathrm{ul}} & =A_{\mathrm{ul}}-A_{1} \approx A_{\mathrm{ul}}=A_{\text {Friedel }} .
\end{aligned}
$$

g) Laws of probability of locking and unlocking: We have measured 145 values of waiting times in the locking position, for screw dislocations of constant length, subjected to a constant stress (all measurements were performed in the same area, and during a short time interval). The results are plotted in figure 13a. For a better understanding, it can be imagined that all dislocations are locked at $t_{\mathrm{B}}=0$ and progressively escape. Under such conditions, the number

a)
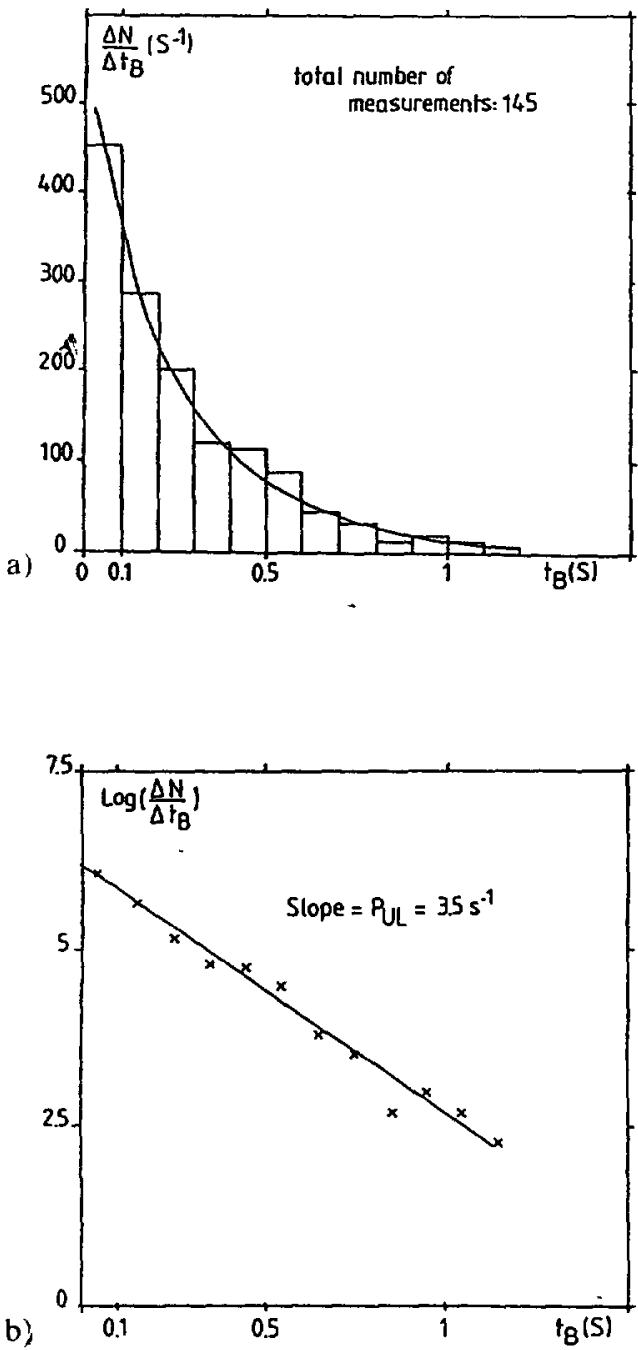

c)

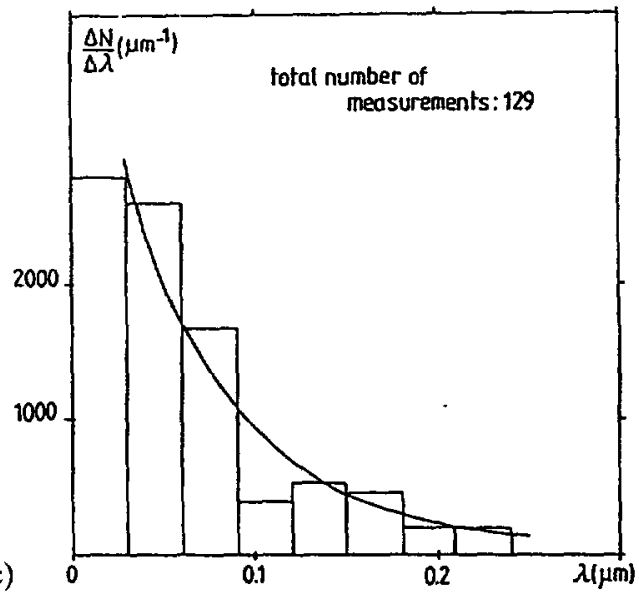

d)

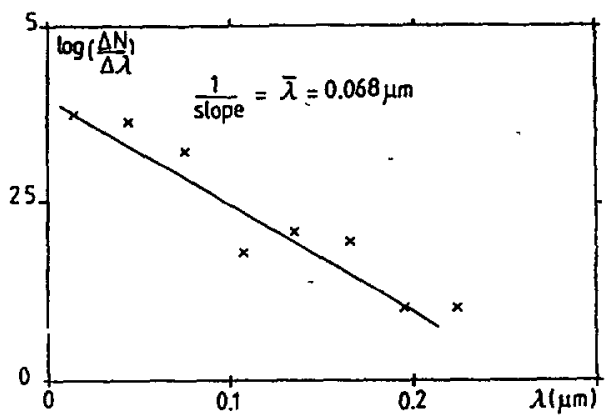

Fig. 13. - Laws of probability of locking and unlocking, * Waiting time measurements in the locked configuration : a) linear scale, b) semi-logarithmic scale. * Jump length measurements in the unlocked configuration : c) linear scale, d) semi-logarithmic scale. 
$\Delta N\left(t_{\mathrm{B}}\right)$ of dislocations which are unlocking between $t_{\mathrm{B}}+\Delta t_{\mathrm{B}}$ decreases exponentially, according to the simple law :

$$
\frac{\Delta N\left(t_{\mathrm{B}}\right)}{\Delta t_{\mathrm{B}}}=C \exp \left(-P_{\mathrm{ul}} t_{\mathrm{B}}\right) .
$$

This confirms that each dislocation has a constant probability $P_{\mathrm{ul}}$ of unlocking per unit time, in agreement with the corresponding cross slip model. $P_{\mathrm{ul}}$ is easily obtained from the slope of the logarithmic curve (Fig. 13b) :

$$
P_{\mathrm{ul}}=3.5 \mathrm{~s}^{-1}
$$

The average waiting time is thus $1 / P_{\mathrm{ul}}=0.22 \mathrm{~s}$.

It is not possible to use the same procedure for the dislocation flight time $t_{\mathrm{p}}$, which is too short to be measured. However, it is possible to measure the corresponding jump length $\lambda=V_{\mathrm{p}} t_{\mathrm{p}}$. As the dislocation velocity in the prismatic plane $V_{\mathrm{p}}$ is unknown, but constant at constant stress, the distribution of $\lambda$ must reproduce the distribution of $t_{\mathrm{p}}$.

The results are plotted in figure 13c. Here again, the jump length and thus the waiting time $t_{\mathrm{p}}$ for locking obey a simple exponential law, with a mean jump length $\bar{\lambda}$ of $0.068 \mu \mathrm{m} \mathrm{s}^{-1}$ This result is important, since it proves that locking by cross slip does not occur at regularly spaced obstacles, which would lead to a Gaussian distribution centred on the mean obstacle distance, and stress and temperature independent. On the contrary, it can occur at every crystallographic row, which is confirmed by the influence of stress and temperature on the mean jump length [50, 52]. Moreover it can be remarked that mean jump lengths are not correlated to the average dislocation spacing (they are generally much smaller), which excludes possible effects of long internal stresses on the jerky movement of screw dislocations.

g) Local stress measurements and temperature stress dependence: The local stress acting on individual dislocations has been deduced from classical radii of curvature measurements. These measurements are in full agreement with macroscopic ones.

Local strain rates and local stresses have been measured after strain rate jumps performed on microsamples. It was not possible to detect any variation of the local stress within the uncertainity of our measurements. This only allow us to assert that the microscopic activation area is larger than $50 \mathrm{~b}^{2}$, which is not in contradiction with macroscopic measurements of Régnier (400 $b^{2}$ at room temperature) [53, 54].

2.3 OSERVATION OF LOCKING-UNLOCKING IN DIFFERENT MATERIALS. - In many other metals with different structures ( $\mathrm{BCC}, \mathrm{HCP}, \mathrm{L1}_{2}$ ) locking-unlocking has been more or less clearly pointed out (Fig. 14).

In Iron, the deformation is controlled by the jerky movement of rectilinear screw dislocations (Fig. 14, Louchet [59]). This movement could possibly be explained by the locking-unlocking mechanism.

The prismatic glide of Titanium is controlled by the motion of rectilinear screw dislocations, submitted to a strong friction force which has been identified with the Peierls mechanism, as mentioned above (see Naka for instance [40-42]). However, recent in situ experiments (Farenc and Couret [60]) have shown that the motion of screw dislocations in prismatic planes of Titanium is very jerky between $100 \mathrm{~K}$ and $473 \mathrm{~K}$ (Fig. 14.2) in agreement with a lockingunlocking mechanism. Since frequent cross slip onto pyramidal planes has also been observed in the whole temperature range, the stable core configuration corresponding to locking could be as already proposed by Naka. In that case, the dislocation is simultaneously spread in the 
1) - Fe
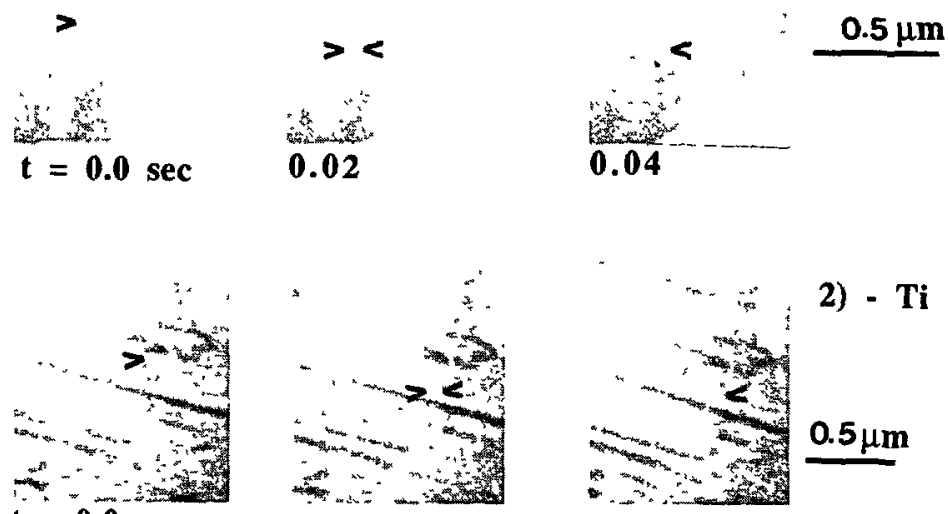

$t=0.0 \mathrm{sec}$

3) $-\gamma^{\prime}($ CMSX2)
0.02

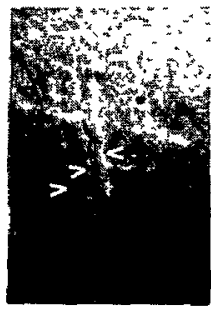

0.02

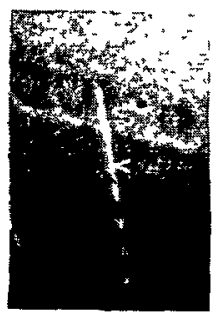

2) - $\mathrm{Ti}$

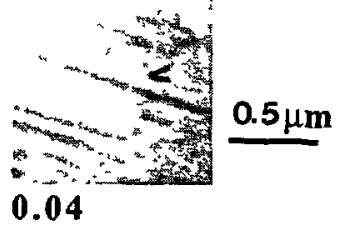

0.04

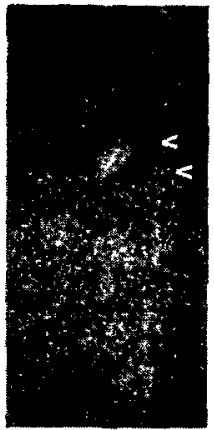

4) $-\mathrm{Ni}_{3} \mathrm{Al}$

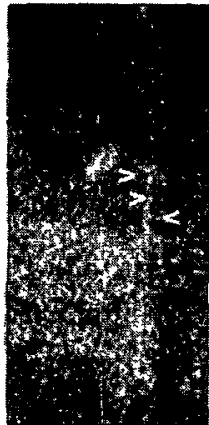

0.02

0.04

$0.1 \mu \mathrm{m}$

$\mathbf{t}=0.0 \mathrm{sec}$

Fig. 14. - Evidence of a locking-unlocking mechanism in several materials : 1) Iron-Louchet [59], 2) Titanium-Farenc and Couret [60],3) Cube glide in the $\gamma^{\prime}$ phase of a superalloy (CMSX2), Clément and Caillard [61-64], 4) Octahedral glide in $\mathrm{Ni}_{3} \mathrm{Al}$, Molénat and Caillard, private communication.

prismatic plane and the two first-order pyramidal ones. The $\sigma^{-2}$ dependence of the activation area obtained by Biget and Saada [43] (Fig. 8) confirms that the activation parameters of the locking-unlocking mechanism are those of the Friedel theory. 
A jerky motion of screw dislocations associated with the locking-unlocking mechanism has also been observed in both cube and octahedral planes of an ordered alloy with the $\mathrm{Ll}_{2}$ structure. In the case of cube glide in the $\gamma^{\prime}$ phase of a superalloy (Fig. 14.3), Clément et al. [61-64] have shown that the locking dislocation configuration consists of two superpartials extended in octahedral planes, and separated by an APB in the cube plane. This is in full agreement with several atomistic calculations [65-67] and high resolution observations [68, 69]. In the octahedral planes of $\mathrm{Ni}_{3} \mathrm{Al}$, screw dislocations with their APB in the glide (111) plane move at room temperature through a serie of jumps and locking positions [70]. More recent in situ experiments also performed under weak beam conditions by Molénat and Caillard [71] have revealed that the jump length is often equal to the width of the APB ribbon (Fig. 14.4).

Remarks : Superkinks have been frequently observed using weak beam electron microscopy in $\mathrm{Ll}_{2}$ deformed crystals. Sun and Hazzledine [72] assume that the movement of dislocations in octahedral planes is controlled by the nucleation and the propagation of superkinks pairs. On the contrary, according to Veyssière in $\mathrm{Ni}_{3} \mathrm{Si}$ [73] and Bontemps and Veyssière in $\mathrm{Ni}_{3} \mathrm{Al}$ [74], dislocations could glide in octahedral planes through the nucleation and the propagation of single superkinks.

It must be noted that in the case of the locking-unlocking mechanism, the formation of superkinks pairs occurs. However, these superkinks are formed only when dislocations cross slip again at the next locking position, namely after the threshold energy has been overcome. Thus, the shape of superkinks is not important for the determination of the activation parameters.

\section{Transition between locking-unlocking and Peierls mechanism.}

The existence of a metastable glissile configuration is at the origin of the difference between the Peierls mechanism described in the first part of this article, and the locking-unlocking one. In both cases, screw dislocations are locked in a stable configuration, and cross slip onto their glide plane with the help of stress. In the case of locking-unlocking, dislocations can move in their glissile metastable configuration over long distances (several Peierls valleys). In the case of the Peierls mechanism, on the contrary, dislocations are not stable at all in their glide plane and they are locked at each Peierls valley. Then, when a locking-unlocking mechanism is observed at low temperature in a given material, a transition to a Peierls mechanism could occur at higher temperatures, provided the thermal activation becomes large enough to make locking athermal. Such a transition has already been observed in magnesium. In the high temperature range ( $T \geqslant 300 \mathrm{~K}$, Fig. 6), screw dislocations glide according to the Peierls
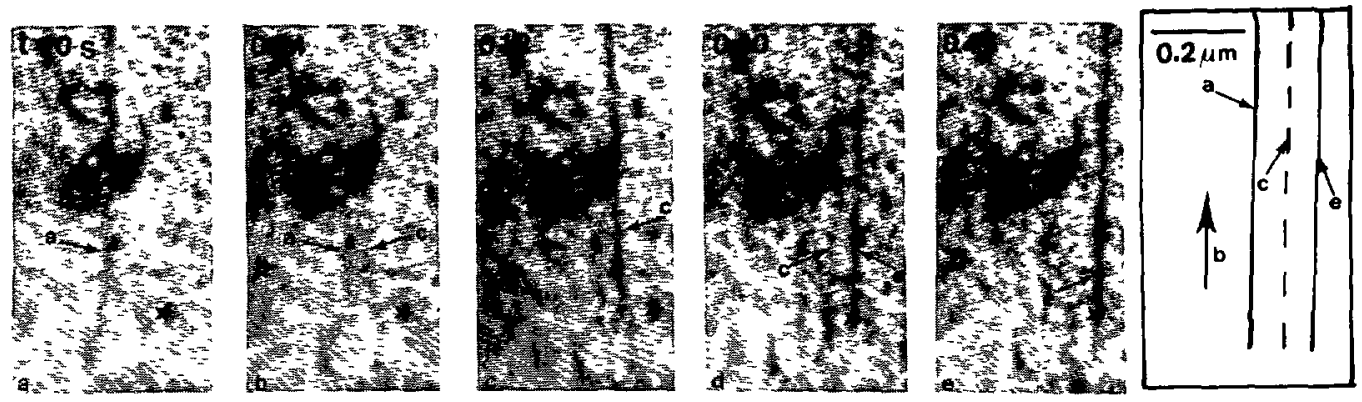

Fig. 15. - Evidence of a locking-unlocking mechanism on screw dislocations in Prismatic planes of Magnesium. Letters refer to successive positions of the same dislocation. $T=150 \mathrm{~K}$. 
mechanism, as described above. However, at lower temperatures, screw dislocations have a jerky glide in accordance with a locking-unlocking mechanism (100 $\mathrm{K} \leqslant T \leqslant 200 \mathrm{~K}$, Fig. 15). Consequently, the Peierls mechanism can be considered as a particular case of the lockingunlocking one, when the temperature is so high that locking becomes athermal. Thus, the Peierls mechanism is surprisingly a high temperature mechanism with respect to lockingunlocking.

A transition between low stress and high stress Peierls mechanisms, which appears as the stress is increased, has been described in the first part of this article. It is characterized by discontinuities on the CRSS and activation area curves, which have been pointed out after theoretical and experimental studies. At the transition, the magnitude of the activation area is small $\left(\leqslant 10 b^{2}\right)$.

Another transition occurring between the locking-unlocking mechanism and the Peierls one is now developed. This transition is fundamentally different from the preceding one, in that it results from an increase of the thermal activation. It should occur at higher temperature. The discontinuities on the CRSS and the activation area curves must also be more pronounced, and the magnitude of the activation area could be very important at this discontinuity.

It seems possible to distinguish between these two transitions only when complete sets of macroscopic and microscopic in situ studies are available. In BCC metals, it is difficult at present to choose between the high stress Peierls/low stress Peierls transition and the lockingunlocking/Peierls one. In Titanium, on the contrary, the observation of a locking-unlocking mechanism at low temperature [60] associated to the measurement of an inverse square law for the applied stress dependence of the activation area [43], and the high activation area value at the transition, indicate that the latter might be associated with the lockingunlocking/Peierls transition. This question will be studied in more details in the near future [60]. A few years ago, a strong discontinuity similar to that measured in Titanium has been pointed out for prismatic glide of Magnesium [8, 9]. The explanation proposed at that time by the authors is now again under discussion in terms of locking-unlocking/Peierls transition.

\section{Friction forces and strength anomalies.}

In this part, attention will be focussed on the correlation between the locking-unlocking mechanism and the strength anomalies observed in several metals and alloys. A general overview of the problem of strength anomalies (which is outside our subject) can be found in previous papers $[4,75]$. Several contributions in this conference will be taken stock on this question.

4.1 Model OF STRENGTH ANOMALy IN BERYLlium [50-52]. - In situ experiments have been performed between $80 \mathrm{~K}$ and $420 \mathrm{~K}$ in single crystals of Beryllium in order to find the true origin of the strength anomaly measured by Regnier et al. [53, 54].

Surprisingly, a jerky movement associated with the locking-unlocking mechanism has been clearly identified in the whole temperature range (Figs. 16, 17). At each temperature, the local stress has been deduced from the measurement of radii curvature of non screw dislocations. Its variation with temperature reproduces very well the shape of the macroscopic curve, including the stress anomaly (Fig. 18). This proves that the behaviour of the bulk material is well reproduced by in situ experiments and that the physical processes at the origin of the stress anomaly are present in thin foils.

Using the method described previously ( $\$ 2.2 . f$ ), the unlocking probability has been measured in the range of the stress increase. It results that $P_{\mathrm{ul}}$ remains constant $\left(3.5 \mathrm{~s}^{-1}\right)$ between $300 \mathrm{~K}$, under a stress of $64 \mathrm{MPa}$, and $240 \mathrm{~K}$, under a stress of $54 \mathrm{MPa}$. This behaviour, which is in contradiction with the laws of thermal activation, is at the origin of the 

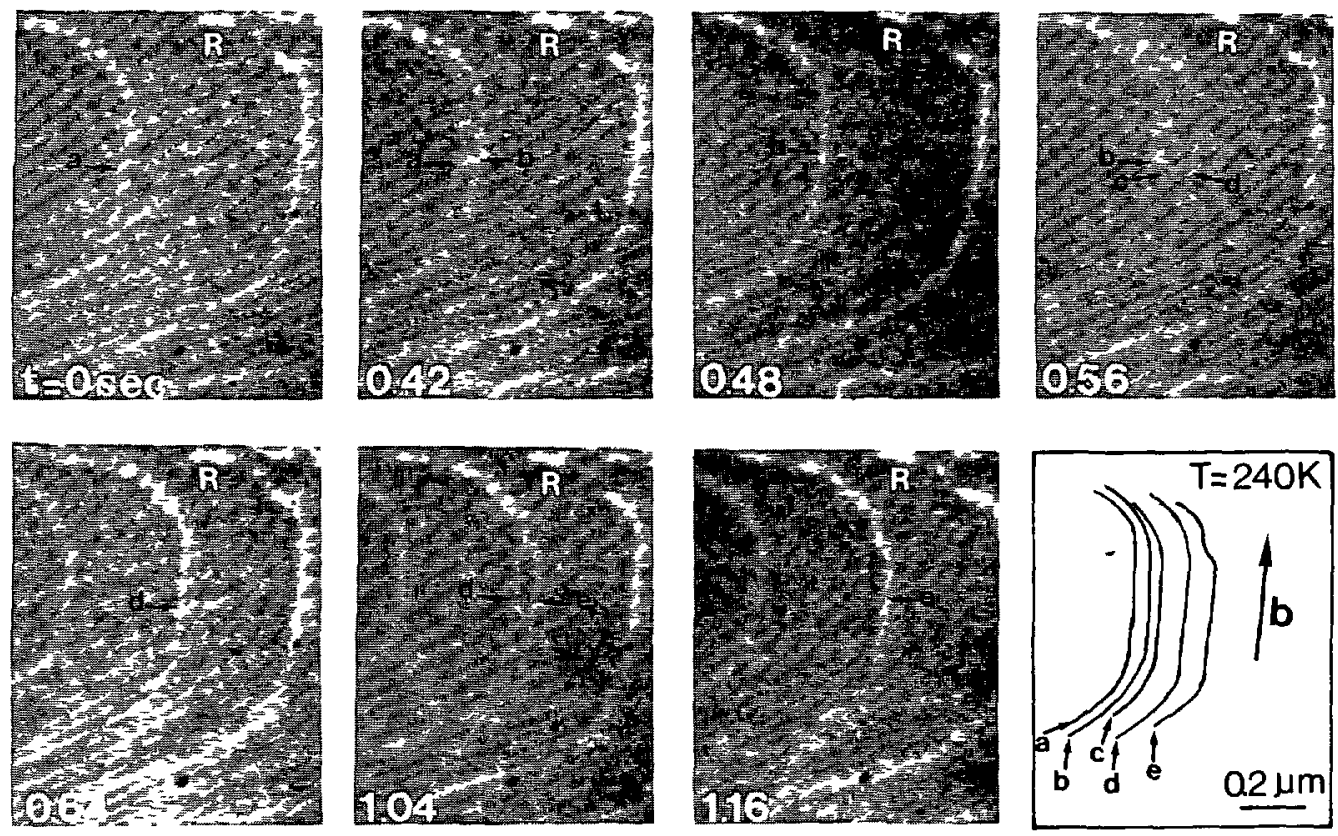

Fig. 16. - Evidence of a locking-unlocking mechanism on screw dislocations in Prismatic planes of Beryllium. Letters refer to successive positions of the same dislocation. $T=240 \mathrm{~K}$ (domain of the stress anomaly).
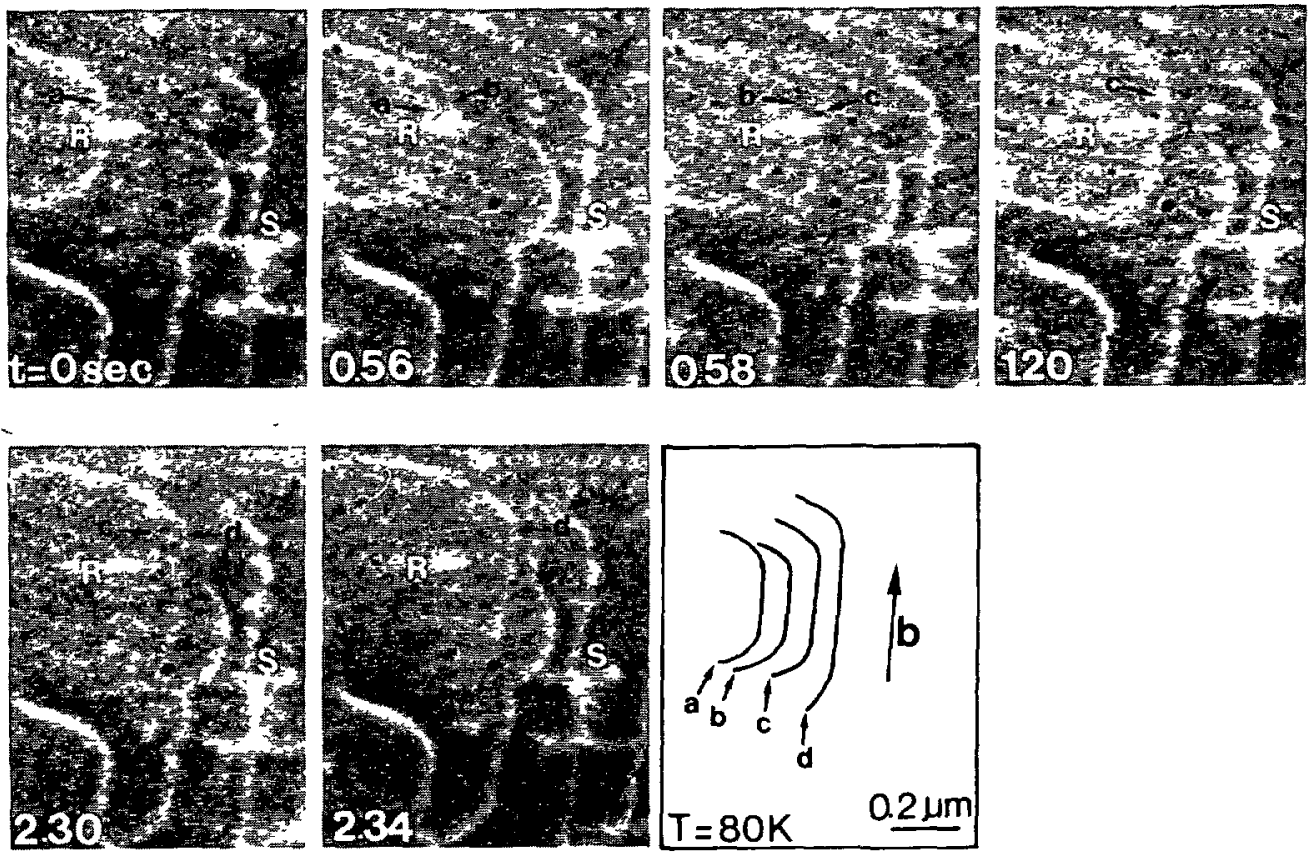

Fig. 17. - Evidence of a locking-unlocking mechanism on screw dislocations in Prismatic planes of Beryllium. Letters refer to successive positions of the same dislocation. $T=80 \mathrm{~K}$. 


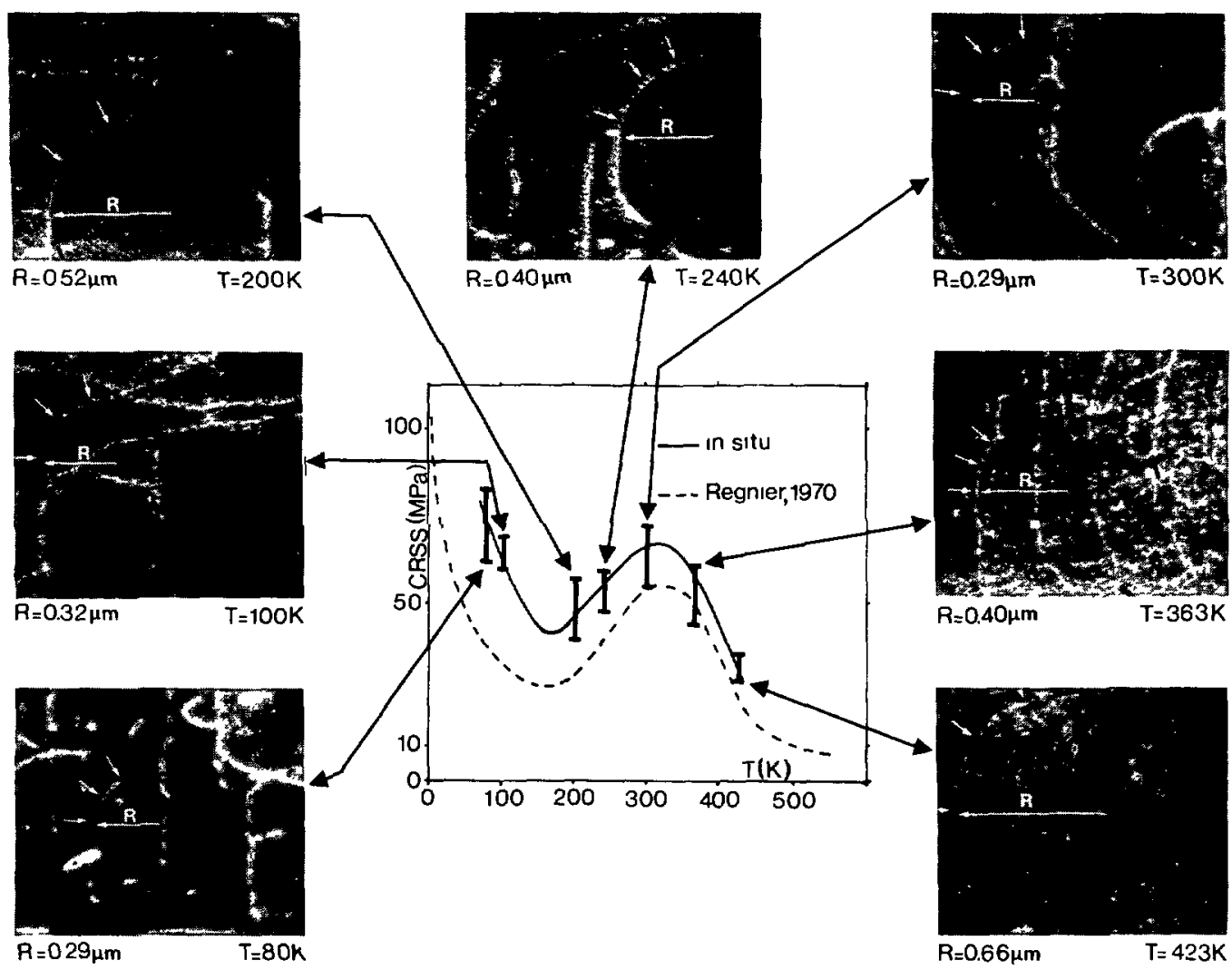

Fig. 18. - Local stress measurements and comparison with macroscopic results. On this picture $R$ is the radius, of curvature of non screw segments of some moving dislocations at different temperatures.

stress anomaly. It could be explained by a continuous evolution of the dislocation core structure. This evolution leads to an increase in the energy necessary to recombine a screw dislocation spread in the basal plane as the temperature is increased. In the elastic approximation, the origin of the strength anomaly is an increase of the dissociation width in the basal plane, correlated to a decrease of the corresponding stacking fault energy which renders cross slip progressively more difficult in spite of the increased thermal activation.

This can be described by a negative entropy term $\Delta S$ according to Couret and Caillard [50, 52] :

$$
\begin{gathered}
\frac{\mathrm{d} \sigma}{\mathrm{d} T}>0 \Leftrightarrow \Delta S<\frac{-\Delta G_{\mathrm{ul}}}{T}<0 \\
\Delta S=\frac{-3}{2} \frac{\Delta G_{\mathrm{ul}}}{2} \frac{\mathrm{d} r}{\mathrm{~d} T}
\end{gathered}
$$

with :

where $\Delta S$ is the entropy term, corresponding to the variation of the reduced energy $r$ for recombining the screw in the basal plane.

4.2 FRICTION FORCES AND STRENGTH ANOMALIES. - When the deformation is controlled by the same mechanism as in Beryllium in the whole temperature range, the strength anomaly is explained by a strong, negative entropy term, corresponding to an evolution of the 
dislocation core structure. This entropy term has been calculated for both the Peierls mechanism and the locking-unlocking one :

$$
\begin{array}{lr}
\text { Peierls : } & \Delta S_{\mathrm{P}} \propto \frac{-1}{2} \frac{\mathrm{d} r}{\mathrm{~d} T} \\
\text { Locking-unlocking : } & \Delta S_{1-\mathrm{ul}} \propto \frac{-3}{2} \frac{\mathrm{d} r}{\mathrm{~d} T} .
\end{array}
$$

It can be noted that $1 / 2$ and $3 / 2$ are the exponents of the reduced energy $r$ for recombining the dislocation in the expressions of the corresponding activation energies. The larger this exponent, the stronger the corresponding entropy for a given variation of $r$ as function of $T$, and the easier the formation of a strength anomaly. A strength anomaly is thus more probable when the deformation is controlled by the locking-unlocking mechanism than by the Peierls mechanism. In the same way, even if the correlation is not direct, the transition from the locking-unlocking mechanism to the Peierls mechanism described above facilitates the decrease of the CRSS.

\section{Conclusion.}

50 years after its first formulation, the Peierls friction force model appears still applicable to metals and alloys. It has been continuously improved, and appears now as one of the best understood dislocation mechanisms. One important step was to introduce non planar configurations on moving dislocations which have been confirmed later by core structure computations and electron microscopy. Another improvement is the extension of the Peierls mechanism to the locking-unlocking mechanism, on the basis of in situ observation of dislocation movements in several metals and alloys. The Peierls mechanism thus appears as a limit of the locking-unlocking one, in the case of an athermal locking process at high temperatures. Locking-unlocking also makes easier the formation of strength anomalies, when the recombining energy of dislocations increases with increasing temperature. All these processes certainly play an important role in the mechanical properties of many metals, alloys, and ordered alloys.

\section{Acknowledgments}

The authors are grateful to F. Louchet, N. Clément, S. Farenc and G. Molénat for stimulating discussions.

\section{References}

[1] Escaig B., J. Phys. Colloq. 35 (1974) C7-151.

[2] VITEK V., Dislocations and Properties of Real Materials, Ed. Physical Society (Arrowsmith, Bristol) 1985, p. 30.

[3] Duesbery M. S., Dislocations in Solids, Ed. F. R. N. Nabarro (1989).

[4] VeYssiere P., Mechanisms and mechanics of plasticity, Ed. J. Castaing, J. L. Strudel and A. Zaoui, Editions de Physique, Revue Phys. Appl. 4 (1988) p. 431.

[5] Duesbery M. S. et Hirsch P. B., Dislocation dynamics, Ed. A. R. Rosenfield, G. T. Hahn, A. L. Bement, R. I. Jaffee (McGraw-Hill book Company) 1967, p. 57 :

[6] Kubin L. P., Reviews on the Deformation Behaviour of Materials, Ed. P. Feltham 1 (1976) p. 244.

[7] Kubin L. P., Reviews on the Deformation Behaviour of Materials, Ed. P. Feltham 4 (1982) p 181.

[8] Couret A. and Caillard D., Acta. Met. 33 (1985) 1447.

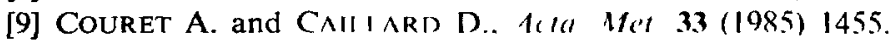


[10] Caillard D. and Martin J. L., Revue Phys. Appl. 22 (1987) 169.

[11] Bonneville J., Caillard D., Carrard M. and Martin J. L., Mechanisms and mechanics of plasticity, Ed. J. Castaing, J. L. Strudel and A. Zaoui, Editions de Physique, Revue Phys. Appl. 23 (1988) p. 461.

[12] Caillard D. and Martin J. L., J. Phys. 50 (1989) 2455.

[13] Peierls R. E., Proc. Phys. Soc. 52 (1940) 23.

[14] Nabarko F. R. N., Proc. Phys. Soc. 59 (1947) 256.

[15] Seeger A., Philos. Mag. 1 (1956) 651.

[16] HiRsCh P. B., 5th Int. Cong. on Crystallography, Cambridge (1960) p. 139.

[17] Yoshinaga H. and HoRIUCHI R., Trans. Jap. Inst. met. 5 (1963) 14.

[18] Kossowsky R. and Brown N., Acta. Met. 14 (1966) 31.

[19] Beardmore P. and Hull D., J. Less. Com. Met. 93 (1965) 168.

[20] Kubin L. P. and Jouffrey B., Philos. Mag. 27 (1973) 1369.

[21] WARdFlynN P., MOTE J. et DoRn J. E., Trans. AIME 221 (1961) 1148.

[22] Stohr J. F., Thèse d'Etat, Université d'Orsay (1972).

[23] Stohr J. F., Regnier P. and Dupouy J. M., Mémoires Scientifiques, Rev. Metallurg., LXVIII 1 (1971) 49.

[24] EsCaIG B., Phys. Stat. Sol. 28 (1968) 463.

[25] Friedel J., Inst. Stresses and Fatigue in Metals, Ed. G. M. Rassweiler and W. L. Grube (Elsevier, Amsterdam) 1959, p. 220.

[26] Seeger A., Z. Metallk. 72 (1981) 369.

[27] Seeger A., Dislocations 1984, Ed. P. Veyssiere, L. P. Kubin and J. Castaing, Editions du CNRS (1984) p. 141.

[28] Schoeck G. and Puschl W., Proceedings of the 8th International Conference of the Strength of Metals and Alloys, Ed. P. O. Kettunen, T. L. Lepistö, M. E. Lehtonen (Pergamon Press) 1 (1988) p. 239.

[29] Escaig B., J. Phys. 28 (1967) 171.

[30] Werner M. and Seeger A., Proceedings of the 8th International Conference of the Strength of Metals and Alloys, Ed. P. O. Kettunen, T. K. Lepistö, M. E. Lehtonen (Pergamon Press) 1 (1988) p. 173.

[31] Ackermann F., Mugrabi H. and Seeger A., Acta. Met. 31 (1983) 1353.

[32] Duesbery M. S., Proceeding of the Symposium on the Structure and Properties of Crystal Defects, Ed. V. Paidar and L. Lejcek, Elsevier (1983) p. 148.

[33] Duesbery M. S., Acta. Met. 31 (1983) 1747.

[34] Duesbery M. S., Acta. Met. 31 (1983) 1759.

[35] Louchet F., Thèse d'Etat, Université de Toulouse (1976).

[36] Louchet F., Kubin L. P. and Vesely D., Philos. Mag. A 39 (1979) 433.

[37] Ikeno S. and Furubayashi E., Phys. Stat. Sol. 12 (1973) 611.

[38] Furubayashi E., J. Phys. Soc. Japan 27 (1969) 130.

[39] Puschl W., Schoeck G. and Kirchner H. O. K., Philos. Mag. A 56 (1987) 553.

[40] Naka S., Thèse d'Etat, Université de Paris Sud (1983).

[41] Naka S. and Lasalmonie A., J. Mat. Sci. 18 (1983) 2613.

[42] Naka S. and Lasalmonie A., Costa P. and Kubin L. P., Philos. Mag. A 57 (1988) 717.

[43] Biget M. P. and SAadA G., Philos. Mag. A 59 (1989) 747.

[44] Le Hazif R., Dorizzi P. and Poirier J. P., Acta. Met. 21 (1973) 903.

[45] Le Hazif R. and Poirier J. P., Acta. Met. 23 (1975) 865.

[46] Carrard M., Thèse de Doctorat, Lausanne (1985).

[47] Carrard M. and Martin J. L., Philos. Mag. A 56 (1987) 391.

[48] Carrard M. and Martin J. L., Philos. Mag. A 58 (1988) 491.

[49] Couret A. and Caillard D., Acta. Met. 36 (1988) 2515.

[50] Couret A., Thèse de Doctorat (1985).

[51] Couret A. and Caillard D., Philos. Mag. A 59 (1989) 783.

[52] Couret A. and Caillard D., Philos. Mag. A 59 (1989) 801.

[53] Regnier P., Thèse d'Etat, Université d'Orsay (1969). 
[54] Regnier P. and Dupouy J. M., Phys. Stat. Sol. 39 (1970) 79.

[55] Legrand B., Thèse d'Etat, Université Paris VI (1984).

[56] Legrand B., Philos. Mag. B 49 (1984) 171.

[57] HuG G., Thèse de Doctorat, Paris Sud (1988).

[58] Hug G., Loiseau A. and Veyssiere P., Philos. Mag. A 57 (1988) 499.

[59] LOUCHET F., Private communication (1990).

[60] FARENC S. and CouRET A., unpublished results (1990).

[61] Clement N., Caillard D., Lours P. and Coujou A., Proceedings of the 8th International Conference of the Strength of Metals and Alloys, Ed. P. O. Kettunen, T. K. Lepistö, M. E. Lethonen, Pergamon Press, 1 (1988) p. 205.

[62] Caillard D., Clement N. and Couret A., Microscopy in Plasticity and Fracture Research of Materials. Edited by U. Messerschmidt, F. Appel, J. Heydenreich et V. Schmidt (Akad. Verlag Berlin) 1990, p. 13.

[63] Clement N., Couret A. and Caillard D., to appear in Philos. Mag.

[64] Clement N., Molenat G. and Caillard D., to appear in Philos. Mag.

[65] Yamagushi M., Paidar V., Pope D. and Vitek V., Philos. Mag., A 45 (1982) 867.

[66] Kar'kina L. Ye., Grinberg B. A. and Yakovenka L. I., Phys. Met. Metall. 61 (1986) 63.

[67] Yoo M. H., Daw M. S. and Baskes M. I., A. S. M. Proceedings on Atomistic Modelling in Materials, Beyond Pair-Potential, Chicago (Plenum Press) 1989.

[68] Baluc N., Stoiber J., Bonneville J. and Martin J. L., Proceedings of 4th Israeli Material Engineering, Beersheva 24 (1988) 269.

[69] Crimp M. A. and Hazzledine P. M., High Temperature Ordered Intermetallic Alloys III, Ed. C. C. Koch, C. T. Liu, N. S. Stoloff, A. I. Taub, Materials Research Society Proceedings, Pittsburg P. A. 133 (1989) 131.

[70] Caillard D., Clement N., Couret A., Lours P. and Coujou A., Philos. Mag. Lett. 58 (1988) 263.

[71] Molenat G. and Caillard D., to appear in Philos. Mag. (1991).

[72] Sun Y. Q. and Hazzledine P. M., Philos. Mag. A 58 (1988) 603.

[73] VeYsSIERE P., Proceedings Mat. Res. Soc. Symp. 133 (1989) 175.

[74] Bontemps C. and Veyssiere P., Philos. Mag. Lett. 61 (1990).

[75] POPE D. P. and Ezz S. S., Int. Metals Rev. 29 (1984) 136. 